\title{
A Criticism of Tests Requiring Alternative Responses
}

\section{H. H. Hahn}

To cite this article: H. H. Hahn (1922) A Criticism of Tests Requiring Alternative Responses, The Journal of Educational Research, 6:3, 236-241, DOI: 10.1080/00220671.1922.10879299

To link to this article: http://dx.doi.org/10.1080/00220671.1922.10879299

曲 Published online: 15 Dec 2014.

Submit your article to this journal $₫$

$Q^{1}$

View related articles 


\title{
A CRITICISM OF TESTS REQUIRING ALTERNATIVE RESPONSES
}

\author{
H. H. HAHN \\ State Normal School, Wayne, Nebraslca
}

Before further use is made of "Yes-No Questions," "SameOpposite Tests," “Alternative Questions," or "True-False Statements" for testing mental ability or achievement in subject matter, the nature and reliability of such tests should once more be critically examined. In this article this form of tests will be discussed, first, as to its accuracy and, second, as to its influence on teaching when used to measure achievement.

Obviously one of its dangers is the guessing factor. Because the right answer is either "Yes" or "No," "True" or "False," "Same" or "Opposite," one has a chance of guessing one-half of the answers correctly. For this reason an attempt must be made in scoring to eliminate the effect of guessing. The method adopted is to subtract the wrong from the right answers, and to accept the remainder as an accurate measure of ability or achievement. But does subtracting the wrong answers from the right eliminate the effect of guessing from the test?

If one holds that by subtracting the wrong from the right answers one eliminates the guessing factor, no more and no less, one must assume that individuals in such tests always guess an even number of times; for if they should guess an odd number of times the effect of guessing could not be wholly eliminated by this method. One must further assume that if an individual happens to guess wrong the first time his second guess must be right, his third wrong, his fourth right, and so on, guessing wrong and right alternately; for if he should guess wrong or right twice in succession, the method could not eliminate the guessing effect. That the law of chance does not operate even approximately in this way can easily be demonstrated.

For the following experiment seventy buttons were used. These buttons were alike in every way except that thirty-five 
were white and thirty-five were black. They were placed in a small paper sack and thoroughly mixed. Then, a blindfolded person drew out twenty-five buttons, one by one, the sack being shaken well after each drawing. This was repeated 25 times with the results shown in Table I. In this experiment the 25 repetitions of the performance are to represent 25 individuals taking a yes-no test. The white and black buttons indicate wrong and right guesses, respectively. Therefore, in Table I $w$ means white button or wrong guess, and $b$ means black button or right guess. The capital letters at the left of the table indicate the 25 performances, and the numbers at the top indicate the number of drawings. If we assume now that each indi$\approx$ vidual guessed five times in answering the 25 questions (the first five answers being the guesses), and if we score the results by the method of eliminating the guessing factor, we find that the respective scores of the individuals tested are as follows: $0,{ }_{5}$, o, o, 5, o, 5, o, 5, o, o, o, 25, 15, o, I5, 5, 5, 5, o, 5, 15, 5, 5, 5 .

TABLE I.-RESULTS OF DRAWING 25 BUTTONS 25 TIMES FROM A BAG CONTAINING 35 WHITE AND 35 BLACK BUTTONS

$\begin{array}{lllllllllllllllllllllllll}1 & 2 & 3 & 4 & 5 & 6 & 7 & 8 & 9 & 10 & 11 & 12 & 13 & 14 & 15 & 16 & 17 & 18 & 19 & 20 & 21 & 22 & 23 & 24 & 25\end{array}$

\begin{tabular}{l|lllllllllllllllllllllllll}
\hline \\
$\mathrm{a}$
\end{tabular}


The median of the whole group is increased by 5 and the average by 6 . If each guesses seven times, their respective scores are increased by $5,15,5,0,0,5,15,0,5,0,0,5,25,25,0,15$, $5,5,15,5,15,15,0,15$. In this case the median is increased by 5 and the average by 8 . If every answer is a guess, then their respective scores are $45,5,0,0,0,0,0,0,0,25,5,5,45,5,25$, $\mathrm{O}, 5, \mathrm{I}_{5}, \mathrm{I}_{5}, 5, \mathrm{O}, \mathrm{I}_{5}, 5,35,5$. The median of the group is 5 and the average is 10. 4. Eight guesses per individual would increase the median by Io and several individual scores by 30 .

Of course, guessing by the human mind is not so mechanical a process as drawing out buttons, but the more complex activity is likely to be the more irregular. It is true that when the individual guesses "No" several times in succession it prepares him for a "Yes"; but this tendency to alternate on the part of the mind is likely to be offset by the fact that when several white buttons are drawn out in succession the black buttons become more numerous than the white. This is not true of the "Yes" and "No" supply. Then, too, mind-sets are likely to increase the irregularity. They are permanent and operate in the same direction throughout the entire test. In all probability the law of chance would not operate again as it did above, but no one can doubt that it would refuse to perform as the advocates of the test in question assume it to operate.

But if one argues that the guessing factor and no more is eliminated by subtracting the wrong answers from the right, one must still further assume that every zorong answer is a guess; otherwise, if the wrong answers are subtracted, they will cancel not guesses but actual achievements. That only guesses cause wrong answers no one would care to assume. To justify the test one must assume, in the fourth place, that just because a certain number of answers are wrong, the same number of right answers must be guesses. If Io answers are wrong and Io right, is one justified in the assumption that the individual tested is in possession of no facts?

But the guessing factor is not the only reason why such a test cannot measure accurately mental ability or achievement. In the first place, the test with its method of scoring credits 
negative achievement, a kind of achievement that has little, if any, social value. For instance, "No" as an answer to the question, "Is warm air heavier than cold air?" is scored as correct. It shows on the face of it that the individual knows warm air is not heavier than cold air. But does the answer show that he knows cold air is heavier than warm air? His inference is correct if he thinks there is no difference between the two in weight. This objection holds with reference to every question or statement to which the right answer is "No" or "False" if it is used for the purpose of testing information. Is it possible to find out what a thing is by asking what it is not?

In the second place, the test credits dependent achievement. It credits identification of correct answers but not their production. For instance, one might be unable to answer the question, "What are intermittent sounds?" but might be able to identify the answer immediately when the question is stated, "Are intermittent sounds discontinuous?" This objection holds with reference to every question or statement to which the right answer is "Yes" or "True" if it is used for the purpose of testing information.

What then does the final score of such tests represent? No one knows. That it cannot even approximately represent real ability or actual achievement has been shown. Nothing important, therefore, should be done on the basis of the score. Such a test should not be used for determining the mental ages of children, for vocational purposes, for classifying children for school work, for studying individual differences, or for diagnostic and remedial work. The statement that the test should not be used for diagnostic purposes may need further explanation. In a general way such a test may indicate weakness or strength on the part of pupils in a certain unit of work, but this is all it can do. For instance, if 15 answers to a test are right and 9 are wrong, the wrong answers do, of course, show weakness on specific points. But it is assumed that 9 of the correct answers are guesses. Which 9? The teacher cannot determine by the test what children do know, and therefore it is not a good diagnostic test. 
When used in school as an achievement test, what is its influence on teaching? What influence it has is reactionary. In the first place, it cannot test the most important thing about a fact or principle. It is important to know that warm air is not heavier than cold air, but it is much more important that the pupil should know why it is not. It is important to know that seaports have a more uniform climate than inland cities, but it is more important to know why. There are no "why's" and "wherefore's" in such tests, and without these the school sinks again to the dead level of memorizing facts. In the second place, it does not encourage organization of subject matter. The exercises are not large enough in scope. Most of them call for answers consisting of single facts. A third reason why its influence is reactionary is found in the fact that it does not encourage problem or project teaching. How many of the exercises in such tests would make a good problem or project in the form in which they occur? Lastly, it uses exclusively the form of question that is condemned in nearly every book on pedagogy, the form of question that can be answered by "Yes" or "No" or their equivalents. How would a teacher be rated these days who would conduct a recitation on the pronoun by using such questions as "Does a pronoun express action?", "Is a pronoun a noun?", "Are there four classes of pronouns?", "Are some pronouns called personal pronouns?" There are other reasons, but enough have been given to show that what influence such tests have on teaching is reactionary.

And why such tests? The principal reason for their use is to avoid trouble in answering questions and scoring answers. There is no 'royal road' to answering real questions and scoring real answers. 